\section{A chance to cut is a chance to ease suffering}

\author{
Sarah Cottrell-Cumber
}

In the setting of acute care surgery, we meet our patients at a time when their life is filled with uncertainty. The head bleed in room 101 is a grandmother who wants to see her grandchildren graduate high school; the open abdomen in ICU 2 is a gentleman who was on the way home from a work when he was involved in a drive-by shooting; the enterocutaneous fistula in ED 18 is a mother to two toddlers who developed wound complications after an emergent bowel resection. Patients are people long before they become patients. They have friends and families, values and aspirations. Because of the unexpected events, oftentimes out of their control, our patients find their futures filled with uncertainty-they no longer feel like the person they were.

I subscribe to the belief that a person is a unit composed of body, mind, and spirit; each facet must be addressed to ensure good health. I did not enter residency with plans to pursue trauma and acute care surgery, but through my exposure to diverse procedures, high acuity scenarios, and intensive critical thinking I have found a passion for the field. It is an all-encompassing patient population, of diverse ages, socioeconomic divisions, and racial and ethnic backgrounds, that could, at any moment, require emergent surgical care. Very rapidly, patients find themselves at their sickest, most vulnerable, and in a time of most need. All the visions for their life cease to be or have substantially changed in an instant. And it is this patient population in which I want to fully address all aspects of my patients' physical, mental, and spiritual health needs.

Surgeons are often taught the old adage that "a chance to cut is a chance to cure". I would rephrase that as "a chance to cut is at a minimum a chance to ease suffering". All surgical procedures have risk, with no

Department of Surgery, University of Mississippi, Jackson, Mississippi, USA

Correspondence to Dr Sarah Cottrell-Cumber; scottrellcumber@umc.edu procedure being truly "benign". Surgeons can either improve or hurt a patient's quality of life with just one cut. We often have blinders on to what the patient and family genuinely want since we are trained to focus on the intervention at hand. Palliative care is the completion of that goal to ease suffering by bringing humanism and communication into interactions where our patients feel human again. Surgical palliative care has been hailed as the fourth service component of acute surgery with core offerings of prognostication, communication, and symptom management. These pillars are essential for aiding in the management of unexpected injury, suffering, and uncertainty of patients and their loved ones.

I have a particular interest in trauma and critically ill surgical patients with earlier integration of palliative care in the ICU setting with clear aligned goals of care and quality of life. Data show that involving palliative principles in the surgical ICU results in decreased length of stay, improved communication with families and patients, and earlier setting of goals of care, without increasing in-hospital mortality. The pervasiveness and destabilizing nature of trauma and emergency general surgery leaves patients with acute and chronic physical, emotional, and spiritual pain. Incorporation of palliative care principles fosters continued care, education, and support as patients and their families adjust to new routines and barriers in their lives.

The burden of emergency surgery is increasing, and so is the long-lasting burden on patients. Through the utilization of palliative care in the acute surgery environment, I hope to continue the expansion of that fourth service component. The incorporation of these principles and personnel can have tremendous impact on physical, mental, and spiritual needs of our patients which can restore quality to their life after suffering and uncertainty.
I intend to complete fellowships in hospice and palliative medicine, as well as trauma and surgical critical care. It is my aim to integrate my skills in the academic setting to reach both patients and surgical trainees with education about the benefits of surgical palliative care. I hope to gain communication skills, a knowledge base founded in symptom management, and engage with multidisciplinary colleagues through a hospice and palliative medicine fellowship. I am confident this will strengthen me as a physician and surgeon, and allow me to provide well-rounded, patient-focused care and to always ensure my patients feel human.

Contributors SC-C conceived, wrote, edited, and submitted the manuscript.

Funding The authors have not declared a specific grant for this research from any funding agency in the public, commercial or not-for-profit sectors.

Competing interests None declared.

Patient consent for publication Not applicable.

Provenance and peer review Commissioned; internally peer reviewed.

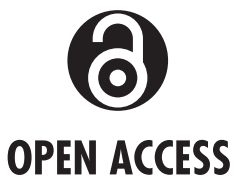

Open access This is an open access article distributed in accordance with the Creative Commons Attribution Non Commercial (CC BY-NC 4.0) license, which permits others to distribute, remix, adapt, build upon this work non-commercially, and license their derivative works on different terms, provided the original work is properly cited, appropriate credit is given, any changes made indicated, and the use is non-commercial. See: http://creativecommons.org/ licenses/by-nc/4.0/

(C) Author(s) (or their employer(s)) 2021. Re-use permitted under CC BY-NC. No commercial re-use. See rights and permissions. Published by BMJ.

Check for updates

To cite Cottrell-Cumber S. Trauma Surg Acute Care Open 2021;6:e000853. doi:10.1136/ tsaco-2021-000853

Received 29 October 2021

Accepted 8 November 2021

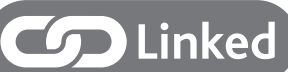

- http://dx.doi.org/10.1136/tsaco-2021-000867

- http://dx.doi.org/10.1136/tsaco-2021-000864

Trauma Surg Acute Care Open 2021;6:e000853. doi:10.1136/tsaco-2021-000853 